\title{
In vitro antioxidant activity and antimicrobial activity against biofilm forming bacteria by the pigment from Desert soil Streptomyces sp D25
}

\author{
Manikkam Radhakrishnan", Venugopal Gopikrishnan, Ganesan Vijayalakshmi, Vanaja Kumar \\ Centre for Drug Discovery and Development, Sathyabama University, Chennai - 600 119. Tamil Nadu, India.
}

\begin{tabular}{l}
\hline ARTICLE INFO \\
\hline Article history: \\
Received on: $04 / 05 / 2016$ \\
Revised on: $29 / 05 / 2016$ \\
Accepted on: $20 / 06 / 2016$ \\
Available online: $28 / 06 / 2016$ \\
\hline Key words: \\
Streptomyces, antioxidant, \\
DPPH method, biofilm and \\
antimicrobial activity.
\end{tabular}

\begin{abstract}
Streptomyces from rare ecosystems is the promising source for secondary metabolites exhibiting diverse biological activities. The present study reports the antioxidant activity and antimicrobial activity against biofilm forming bacteria by the pigment produced from Desert soil Streptomyces sp. D25. Crude pigment from the Streptomyces sp D25 was produced by agar surface fermentation using yeast extract malt extract agar and extracted using ethyl acetate. Antioxidant activity of pigment was tested at $100-500 \mu \mathrm{g} / \mathrm{ml}$ concentration by DPPH and nitric acid scavenging assay. Antimicrobial activity against the biofilm forming bacteria was tested by disc diffusion method. The Streptomyces pigment showed $35.63 \%$ and $96.19 \%$ free radical scavenging activity in DPPH assay and nitric oxide assay, respectively. The results of radical scavenging activity of pigment in DPPH and nitric oxide assay showed its antioxidant potential. In antimicrobial assay, the pigment showed 10$20 \mathrm{~mm}$ inhibition against biofilm forming bacteria at $25 \mu \mathrm{g} / \mathrm{ml}$. Further in vivo studies on this Streptomyces pigment pave the way for its biomedical applications.
\end{abstract}

\section{INTRODUCTION}

Reactive oxygen species (ROS) production occurs during normal cell metabolism. Excessive amount of ROS increases oxidative stress and it can cause deleterious effects such as atherosclerosis, reperfusion injury, cataractogenesis, rheumatoid arthritis, inflammatory disorders and cancer. Antioxidants play an important role in inhibiting and scavenging free radicals, thus providing protection to humans against various infections and degenerative diseases. In order to retard the oxidation process, many synthetic antioxidants such as butylatedhydroxycanisole (BHA), butylatedhydroxytoluene (BHT), and propyl gallate (PG) are being used in clinics. However, these synthetic antioxidants have potential health

* Corresponding Author

Manikkam Radhakrishnan, Centre for Drug Discovery and Development, Sathyabama University, Chennai - 600 119. Tamil Nadu.

Email:mrkactinos@yahoo.com hazards, so it have been attempted to screen alternative antioxidants from natural sources (Lee et al., 2014). Dietary antioxidants have already been shown to be protective against chronic diseases. Modern research is now directed towards natural antioxidants from plants and microorganisms and serves as safe therapeutics (Thenmozhi et al., 2010). Biofilms or microbial communities formed by adherent and cohesive cells on cellular or inert substrata (like medical devices), are involved in $60 \%$ of all infections. These infections tend to be chronic as they resist innate and adaptive immune defence mechanisms as well as antibiotics, and the treatment of biofilm infections presents a considerable unmet clinical need. To date, there are no drugs that specifically target bacteria in biofilms; however, several approaches are in early-stage development. For this reason, innovative anti-biofilm agents with novel targets and modes of action are needed (Oja et al., 2015). Actinobacteria are gram positive bacteria that constitute one of the largest bacterial phyla and they are ubiquitously distributed in both aquatic and terrestrial ecosystems. 
Actinobacteria are of great importance in the field of biotechnology, as producers of plethora of bioactive secondary metabolites with extensive clinical, veterinary, aquaculture and agricultural applications. They have extensive secondary metabolism and produce two-thirds of all naturally derived antibiotics in current clinical use as well as many anticancer, antifungal and antiviral compounds (Barka et al., 2016). With this view the present work is focused to test the antioxidant activity and antimicrobial activity of pigment from the Desert soil Streptomyces sp.D25 against biofilm forming bacteria.

\section{MATERIALS AND METHODS}

\section{Description of Streptomyces sp D25}

The soluble yellow-orange pigment producing Streptomyces sp D25 (Figure 1) was isolated from the soil collected from Thar Desert, Rajasthan. The yellow-orange pigment showed promising antimicrobial activity against Gram positive bacteria and anti TB activity in vitro (Radhakrishnan et al., 2014). Viability of this strain was maintained on yeast extract malt extract (YEME) agar slants as well as in glycerol broth.

\section{Production and extraction of pigment}

Pigment from the Streptomyces sp D25 was produced by agar surface fermentation using YEME agar (Radhakrishnan et al., 2015). After 7 days of incubation, the soluble pigment from the agar medium was extraction by solid liquid extraction method using ethyl acetate at 1:2 ratio. The ethyl acetate extract was concentrated using rotary evaporator under reduced pressure and used for testing antioxidant and antimicrobial activity against biofilm forming bacteria.

\section{Screening for antioxidant activity DPPH radical scavenging assay}

The DPPH free radical scavenging assay was conducted based on the method of Rajesh and Natvar (2011). DPPH (1,1diphenyl -2- picrylhydrazyl (H-A) was dissolved in $3.3 \mathrm{ml}$ methanol and it was protected from light by covering the test tubes with aluminum foil. Then about 150 $\mu$ l DPPH solutions were added to $3 \mathrm{ml}$ methanol and absorbance was taken immediately at $517 \mathrm{~nm}$ for control reading. About 100, 200, 300, 400 and 500 $\mathrm{\mu g}$ concentration of crude pigment as well as standard compound (ascorbic acid) was added into each $3 \mathrm{ml}$ of methanol. Then each $150 \mu 1$ of DPPH was added to all the reaction tubes. Absorbance was taken after 15 minutes at $517 \mathrm{~nm}$ on UV-Visible spectrometer, Cyberlab Model using methanol as blank. The DPPH free each radical scavenging activity was calculated using the following formula:

$\%$ scavenging $=\frac{\text { Absorbance of control }- \text { Absorbance of test sample }}{\text { Absorbance of control }} \times 100$

\section{Nitric oxide free radical scavenging activity}

About 100, 200, 300, 400 and $500 \mu \mathrm{g}$ concentration of crude pigment previously dissolved in DMSO, as well as ascorbic acid (standard compound) was taken in separate tubes. About 2.0 $\mathrm{ml}$ of sodium nitroprusside in phosphate buffer saline was added into each tube. The reaction mixture was incubated at room temperature for 150 minutes. After incubation, $5 \mathrm{ml}$ of Griess reagent was added in the each tube including control. The absorbance was measured at $546 \mathrm{~nm}$ on UV-Visible spectrometer using methanol as blank (Rajesh and Natvar, 2011).

$\%$ scavenging/reduction

$=\frac{\text { Absorbance of control }- \text { Absorbance of test sample }}{\text { Absorbance of control }} \times 100$

\section{Screening for antimicrobial activity}

Antimicrobial activity of pigment against the biofilm forming bacteria was tested by disc diffusion method against biofilm forming bacteria previously isolated from marine fouling samples (Gopikrishnan et al., 2013). Five mm diameter filter paper disc impregnated with $25 \mu \mathrm{g}$ of pigment was placed over nutrient agar plates inoculated with biofilm forming bacteria. Activity was tested in triplicate and the mean value was expressed as zone of inhibition in millimetre in diameter.

\section{RESULTS AND DISCUSSION}

Streptomyces $s p$. D25 showed good growth on ISP2 agar with soluble yellow pigment production (Figure 1).

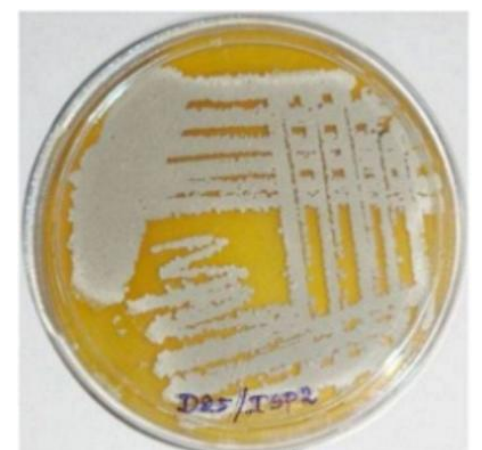

Fig. 1: Growth of streptomyces sp D25 on ISP2 agar.

In DPPH method, the free radical scavenging activity of pigment extracted from the Streptomyces sp D25 was increased with the increasing concentration. From the results, it confirmed that the crude pigment showed maximum of $35.63 \%$ of free radical scavenging activity. The result was graphically represented in figure 2 . In the previous study also the yellow pigment extracted from the novel Streptomyces sp Eri12 from the rhizosphere of Rhizoma curcumae Longae showed $28.89 \%$ radical scavenging activity at $500 \mu \mathrm{g} / \mathrm{ml}$ in DPPH method (Zhong et al., 2011).

In nitric oxide free radical scavenging assay, the Streptomyces pigment showed the dose dependent scavenging/ reductive potential. From the result (Figure 3), when the concentration increases, percentage of scavenging is also increasing linearly for the Streptomyces pigment and ascorbic acid standard. The crude pigment showed maximum of $96.19 \%$ radical scavenging activity in nitric oxide assay. Nitric oxide (NO) has also been involved in a variety of biological functions, including neurotransmission, vascular homeostasis, antimicrobial, and 
antitumor activities. Despite the possible beneficial effects of NO, its contribution to oxidative damage is also reported. This is due to the fact that NO can react with superoxide to form the peroxy nitrite anion, which is a potential oxidant that can decompose to produce $\mathrm{OH}$ and NO (Rajesh and Natvar, 2011).

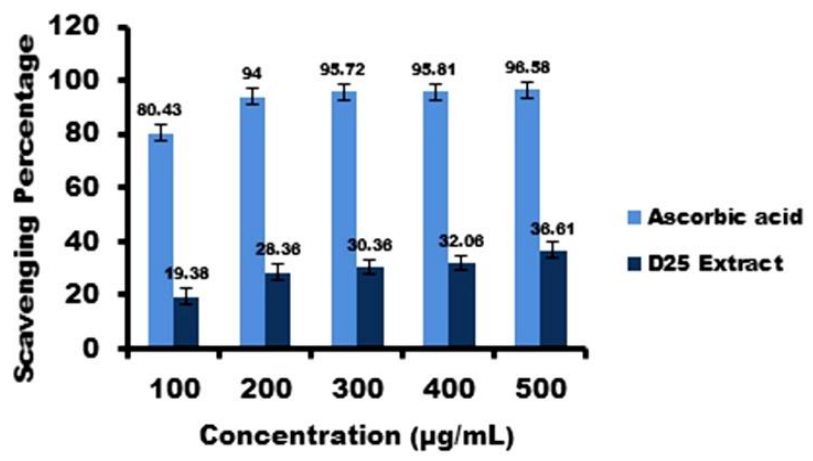

Fig. 2: Antioxidant activity of pigment from streptomyces sp D25 in DPPH method.

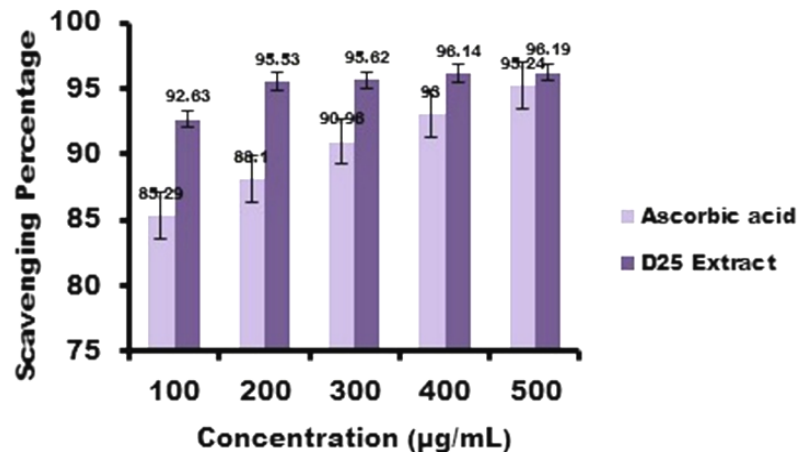

Fig. 3: Antioxidant activity of pigment from streptomyces sp D25 in nitric oxide assay.

Table 1: Antimicrobial activity of Streptomyces pigment D25 against biofilm forming bacteria

\begin{tabular}{lc}
\hline \multicolumn{1}{c}{ Biofilm forming bacteria } & Zone of Inhibitionmm in diameter \\
\hline Staphylococcussp M1 & $16.3 \pm 0.3$ \\
Lactobacillussp M6 & $20.7 \pm 0.6$ \\
Alcaligenssp M28 & $19.3 \pm 0.3$ \\
Bacillussp M38 & $11.7 \pm 0.3$ \\
Micrococcussp M50 & $10.7 \pm 0.3$ \\
Lactobacillussp M51 & $11.7 \pm 0.8$ \\
Pseudomonassp P1 & $15.0 \pm 0.5$ \\
Kurthiasp P3 & $10.0 \pm 0.5$ \\
Lactobacillussp P4 & $16.7 \pm 0.3$ \\
Alcaligenssp P8 & $16.7 \pm 0.3$ \\
Bacillussp P13 & $20.7 \pm 0.3$ \\
\hline
\end{tabular}

Most bacteria can switch between two life styles and exist either as free-living, planktonic cells or as bacterial biofilms that are surface-associated communities of cells embedded in a self produced matrix. The matrix consists of extracellular polymeric substances (EPS), and it is one of the factors contributing to increased tolerance to antibiotics associated with bacterial biofilms (Oja et al., 2015).In antimicrobial testing, the crude pigment extracted in ethyl acetate showed $10-20 \mathrm{~mm}$ inhibition against the biofilm forming bacteria at $25 \mu \mathrm{g} / \mathrm{ml}$ in disc diffusion method (Table 1). Studies on the inhibition of biofilm formation by the streptomyces pigment prove its potential further.

\section{ACKNOWLEDGEMENT}

Authors thank the authorities of Sathyabama University for the research facilities provided.

\section{REFERENCES}

Barka EA, Vatsa P, Sanchez L, Gaveau-Vaillant N, Jacquard C, Klenk H-P, Clément C, Ouhdouch Y, van Wezel GP. 2016. Taxonomy, physiology, and natural products of Actinobacteria. Microbiol. Mol. Biol. Rev. 2016; 80:1-43.

Gopikrishnan V, Pazhanimurugan R, Shanmugasundaram T, Radhakrishnan M, Balagurunathan R. Bioprospecting of actinobacteria from mangrove and estuarine sediments for antifouling compounds. International Journal of Innovation in Science.Engineering and Technology. 2013; 2(7): 2726-2735.

Lee DR, Lee SK, Cho BK, Cheng J, Lee YS, Yang SH, Suh JW. Antioxidant activity and free radical scavenging activities of Streptomyces sp. strain MJM 10778. Asian Pacific Journal of Tropical Medicine.2014; 962-967.

Oja T, Galindo P, Taguchi T, Manner S, Vuorela PM, Ichinose K, Metsä-Ketelä M, Fallarero A. Effective antibiofilmpolyketides against Staphylococcus aureus from the pyranonaphthoquinone biosynthetic pathways of Streptomyces species. Antimicrob Agents Chemother.2015; 59: 6046-6052.

Radhakrishnan M, Gopikrishnan V, Balagurunathan R, Vanaja Kumar. Effect of critical medium components and culture conditions on antitubercular pigment production from novel Streptomycessp D25 isolated from Thardesert, Rajasthan. Journal of Applied Pharmaceutical Science. 2015; 5(6): 15-19.

RadhakrishnanM, Gopikrishnan V Balaji S Balagurunathan R, Vanaja Kumar. Bioprospecting of actinomycetes from certain less explored ecosystems active against Mycobacterium tuberculosis and other non-mycobacterial pathogens.International Scholarly Research Notices. 2014;2014: 9.

Rajesh PM, Natvar PJ. In vitro antioxidant activity of coumarin compounds by DPPH, Super oxide and nitric oxide free radical scavenging methods. Journal of Advanced Pharmacy Education and Research. 2011; 1: $52-68$.

ThenmozhiM, Sindhura S, Kannabiran K. Characterization of antioxidant activity of Streptomyces species VITTK3 isolated from Puducherry Coast, India. J. Adv. Sci. Res. 2010; 1(2): 46-52.

Zhong K, Gao XL, Xu ZJ, Gao H, Fan S, Yamaguchi I, Li LH, and Chen RJ. Antioxidant activity of novel Streptomyces strain Eri12 isolated from the rhizosphere of RhizomacurcumaeLongae. Current Research in Bacteriology. 2011; 4(2): 63-72.

\section{How to cite this article:}

Radhakrishnan M, Gopikrishnan V, Vijayalakshmi G, Kumar V. In vitro antioxidant activity and antimicrobial activity against biofilm forming bacteria by the pigment from Desert soil Streptomyces $s p$ D25. J App Pharm Sci, 2016; 6 (06): 148-150. 